\title{
Influence of uncoated and coated plastic waste coarse aggregates to concrete compressive strength
}

\author{
Heru Purnomo ${ }^{1 *}$, Gandjar Pamudji ${ }^{1}$, and Madsuri Satim ${ }^{l}$ \\ ${ }^{1}$ Civil Engineering Department, Faculty of Engineering, Universitas Indonesia, 16424 Depok, Indonesia
}

\begin{abstract}
The use of plastic waste as coarse aggregates in concrete is part of efforts to reduce environmental pollution. In one hand the use of plastic as aggregates can provide lighter weight of the concrete than concrete using natural aggregates, but on the other hand bond between plastic coarse aggregates and hard matrix give low concrete compressive strength. Improvement of the bond between plastic coarse aggregate and hard matrix through a sand coating to plastic coarse aggregate whole surface is studied. Sand used to coat the plastic aggregates are Merapi volcanic sand which are taken in Magelang. Three mixtures of polypropylene (PP) coarse plastic aggregates, Cimangkok river sand as fine aggregates, water and Portland Cement Composite with a water-cement ratio of $0.28,0.3$ and 0.35 are conducted. Compression test are performed on concrete cylindrical specimens with a diameter of $10 \mathrm{~cm}$ and a height of $20 \mathrm{~cm}$. The results in general show that concrete specimens using plastic aggregates coated with sand have higher compressive strength compared to those of concrete specimens using plastic aggregates without sand coating. The bond improvement is indirectly indicated by the betterment of concrete compressive strength.
\end{abstract}

\section{Introduction}

Nowadays lightweight concrete has been used for building materials. As lightweight aggregate is part of lightweight concrete, lightweight aggregate can be taken from nature such as pumice, coconut shell, perlite etc, and can be made from fly ash, slag or plastic as example. Until now plastic are used daily by the modern community. This phenomenon is due its low production cost, light in weight and relatively easy to form. However as the number of people increase, the plastic waste becomes problem for most of countries around the world.

At world level, plastic production reaches almost 150 million ton per year which in turn 4.8 ton per second according to The Central Pollution Control Board [1]. In Indonesia according to Indonesia Solid Waste Association (InSWA) total plastic garbage in year 2008 has reached 5.4 million ton per year or $14 \%$ from total garbage production. The plastic waste is non biodegradable which in turn creating environmental problem [2].

Transformation of plastic waste to a new production that benefits to the people will decrease the number of unused plastic waste. Transformation of plastic waste into aggregate for concrete making will give benefit not only for environment but also for construction world in view of reducing the own weight of the concrete [3-7]. This effort can be considered as new perspective in research activities in integrating concrete technology and environmental issue. However the weak side of using plastic as coarse or fine aggregates in concrete is in the mechanical properties of that concrete.

According to Saikia and Brito [8], this strength reduction are caused by (a) low bond strength between plastic aggregate surface and cement paste, (b) plastic characteristic which is unable to absorb water, hampering cement hydration reaction as there is limitation of water movement. Choi et al [9] have improved the interface characteristic between plastic aggregate and cement paste by slag (GBFS) addition in plastic aggregate material which in turn strengthens the surface of plastic aggregate as GBFS reacts with calcium hydroxide.

By improving the interface characteristic between surface of plastic aggregate and mortar through enhancement of hardness and texture of surface of plastic aggregate, performance of concrete mechanics will be better. This study covers the development of uncoated and coated plastic coarse aggregate as one of the concrete materials. The coating material chosen is Merapi volcanic sand coming from Magelang located at Java Island, Indonesia. Volcanic sand is considered having higher $\mathrm{SiO}_{2}$ content compared to river sand which in turn it could expand interface zone between aggregates and mortar [10].

\footnotetext{
Corresponding author: herupur@eng.ui.ac.id
} 


\section{Experimental program}

\subsection{Material}

Portland Cement Composite is used to satisfy Indonesian Standard (SNI 15-7064-2004) and European Standard (EN 197-1:2000 (42.5 N \& 42.5 R).

Sand from Cimangkok at West Java, Indonesia is used as fine aggregate. Size of the fine aggregate is less than $9.5 \mathrm{~mm}$ while specific gravity and fineness modulus of the fine aggregate where found to be 2.33 and 2.63 respectively. The percentage of passing is within the limits as per SNI 03-2834-2000.

The coarse aggregate is made from waste of Polypropylene (PP) plastic. Figure 1 shows the shapes of uncoated plastic aggregate. The uncoated aggregate shape is similar to the plastic aggregate developed by Pamudji, G et al. [7]. The aggregate has generally $10 \mathrm{~mm}$ of thickness and, $20 \mathrm{~mm}$ of length and $20 \mathrm{~mm}$ of width. Plastic aggregate is formed by heating the plastic up to the melting point; it is flowed then into the mould by hydraulic pressure. The process itself is conducted using manual injection plastic machine with automatic temperature control. The plastic melting temperature is in range of $1300 \mathrm{C} \pm 100 \mathrm{C}$. After the formation, the plastic aggregate were then cooled.

Once the uncoated coarse aggregate is formed, then it is coated with hot sand by placing the uncoated plastic aggregate into a rotating cylinder. Merapi Volcanic Sand taken at Magelang is used for coating purposes. The final shape of plastic aggregate coated with Merapi sand is shown in Figure 2. It is intended to improve bonding at the interface between coarse aggregate and mortar.

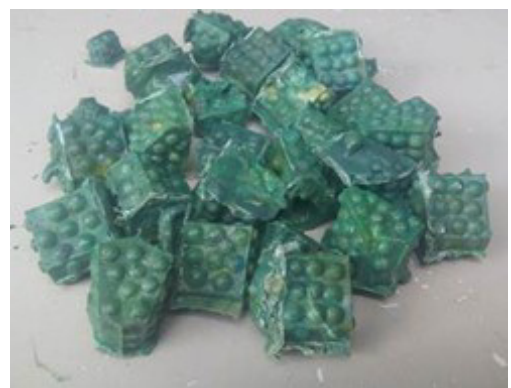

Fig.1. Shape of uncoated plastic aggregate [7]

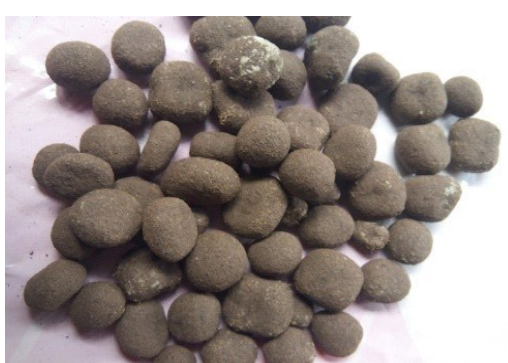

Fig.2. Plastic aggregate coated with sand

\subsection{Mix proportion of concrete}

Proportion of materials is determined using mix design method that is based on absolute volume. From trial mixes, it is obtained series of material mix proportion of concrete containing plastic aggregate, denoted by $\mathrm{M}$ type of mix proportion. Water to cement ratio (W/C) used are $0.28,0.3$ and 0.35 respectively as presented in Table 1 . Superplasticizer (SP) is used to have better workability in mixing the materials for M1 to M3 proportion.

Table 1. Concrete mix proportion

\begin{tabular}{|c|c|c|c|c|c|c|}
\hline Type & W/C & $\begin{array}{c}\text { Cement } \\
(\mathbf{k g})\end{array}$ & $\begin{array}{c}\text { Sand } \\
(\mathbf{k g})\end{array}$ & $\begin{array}{c}\text { Plastic } \\
\text { Aggr. } \\
(\mathbf{k g})\end{array}$ & $\begin{array}{c}\text { Water } \\
\mathbf{( k g )}\end{array}$ & $\begin{array}{c}\text { Admixture } \\
\text { (SP) (kg) }\end{array}$ \\
\hline M1 & 0,28 & 500 & 678 & 411 & 140 & 8 \\
\hline M2 & 0,30 & 500 & 738 & 388 & 150 & 7 \\
\hline M3 & 0,35 & 500 & 738 & 372 & 175 & 5 \\
\hline
\end{tabular}

\section{Results and discussion}

\subsection{Physical properties of material}

Observation of physical properties of sand from Merapi and Cimangkok was conducted on density, water absorption, granular gradation, and fineness modulus. Test result of the physical properties of the sand is presented in Table 2 .

Table 2. Physical properties of sand

\begin{tabular}{|c|c|c|}
\hline \multirow{2}{*}{ Physical characteristic } & \multicolumn{2}{|c|}{ Sand } \\
\cline { 2 - 3 } & Cimangkok & Merapi \\
\hline Specific gravity $\left(\mathrm{g} / \mathrm{cm}^{3}\right)$ & & \\
\hline Apparent & 2.44 & 2.74 \\
\hline Bulk & 2.26 & 2.68 \\
\hline SSD & 2.33 & 2.70 \\
\hline Absorption (\%) & 3.31 & 2.81 \\
\hline Density & 1.39 & 1.45 \\
\hline Fineness modulus (FM) & 2.63 & 3.44 \\
\hline
\end{tabular}

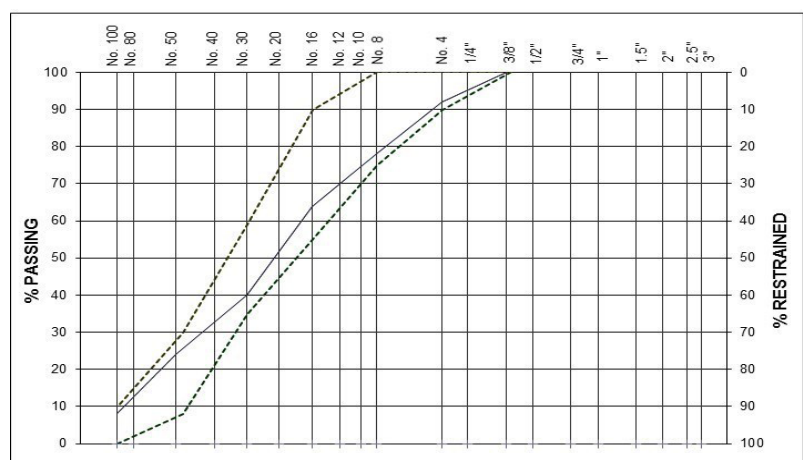

Fig. 3. Graph of Cimangkok sand gradation

While gradation of fine aggregate grains are shown in Figures 3 and 4. The gradation of both types of sand are within the envelope limits. At low percentage passing both sand behave similarly but gradually as the percentage passing grows Merapi sand tends to near the left envelope while that of Cimangkok near the right 
envelope. Specific gravity of Merapi Sand is higher than that of Cimangkok Sand.

Observation of physical properties of uncoated plastic aggregate was conducted on density, bulk density and water absorption. The test result of physical properties of uncoated plastic aggregates is presented in Table 3. Its absorption is in fact very small in percentage.

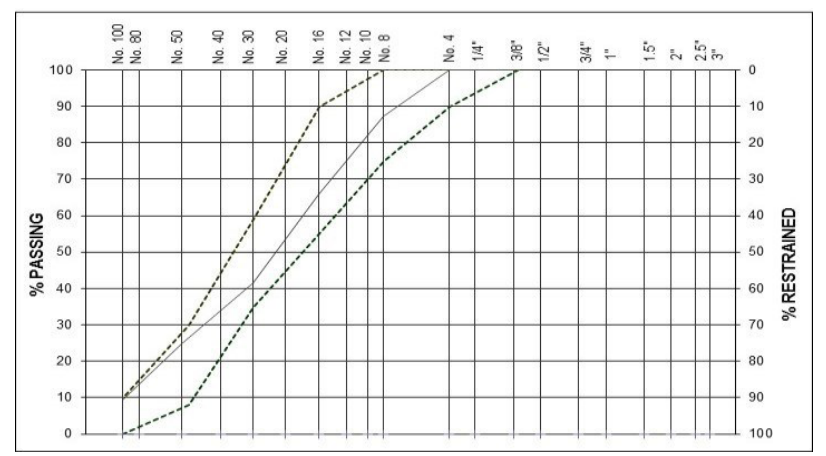

Fig. 4. Graph of Merapi sand gradation

Table 3. Properties of coated plastic aggregate

\begin{tabular}{|l|c|}
\hline \multicolumn{1}{|c|}{ Characteristic of physic } & Plastic aggregate \\
\hline Specific gravity $\left(\mathrm{g} / \mathrm{cm}^{3}\right)$ & \\
\hline Apparent & 1.13 \\
\hline Bulk & 1.07 \\
\hline SSD & 1.12 \\
\hline Absorption (\%) & 0.05 \\
\hline Density & 0.70 \\
\hline Fineness Modulus (FM) & 4.45 \\
\hline
\end{tabular}

\subsection{Compressive strength of plastic cube}

Compressive strength of PP plastic is obtained by compression testing of plastic cube specimens. Using manual injection machine under controlled temperature, plastic cube specimens are made in cubical shape having size of $5 \mathrm{~cm} \times 5 \mathrm{~cm} \times 5 \mathrm{~cm}$.

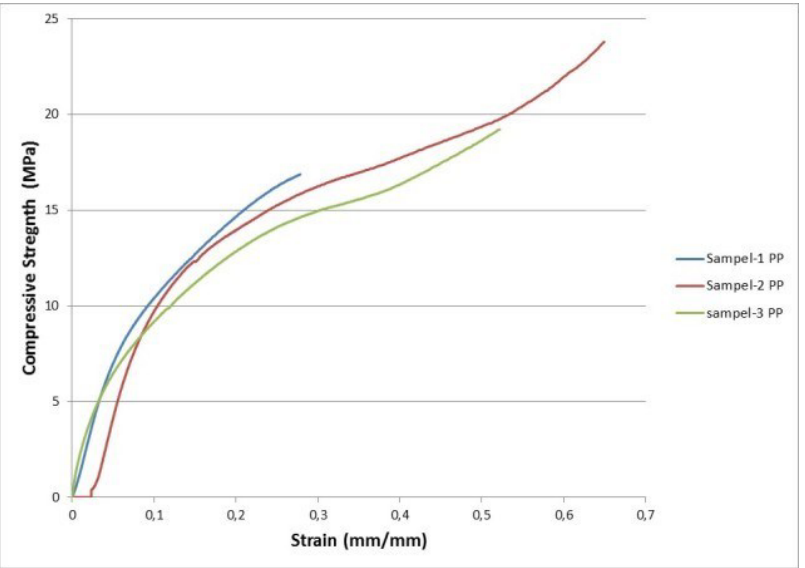

Fig. 5. Curve of - Plastic cube

Results of compressive strength versus strain of PP plastic cubes are shown in Figure 5. All the three curves show similar behavior where stress is still increasing as strain grows bigger. All the cube specimens experienced large deformation without any cracks appeared on the surface of the specimens and the depth of all specimens shortened at large strain.

As there is no concrete crushing phenomenon existed at plastic cube specimen during compression test, the compressive strength of the three PP cubes specimen is taken minimum between 7 to $8 \mathrm{MPa}$ referring to 0.06 strain of the blue sample (specimen 1) linier curve limit.

\subsection{Density of Concrete}

Evaluation of concrete density are performed on 28 days aged concrete cylindrical specimens with a diameter of $10 \mathrm{~cm}$ and a height of $20 \mathrm{~cm}$ that serve for compression testing. Two kinds of concrete specimen are evaluated. The first type is concrete containing uncoated plastic coarse aggregate while the second type of concrete contains Merapi sand coated plastic aggregate. Evaluation result shows that density of concrete containing uncoated plastic coarse aggregate is in general between 10 to $14 \%$ lighter than that containing sand coated plastic coarse aggregate for three kind of water to cement ratios, as presented in Figure 6.

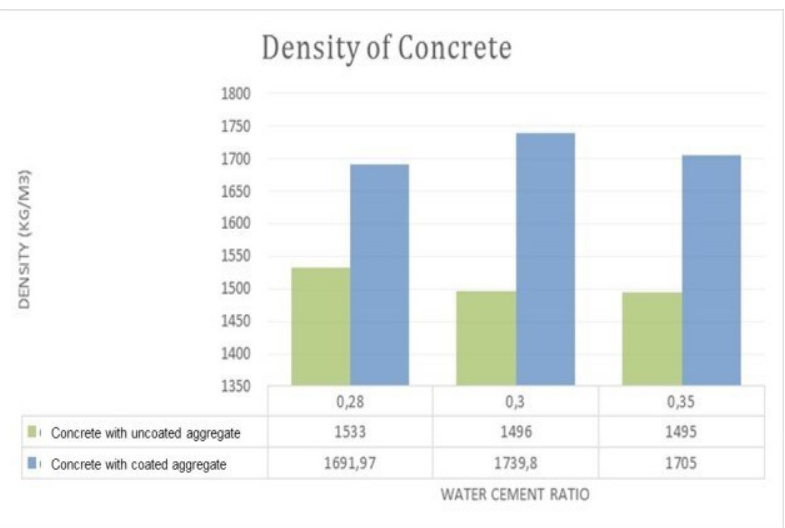

Fig. 6. Density of concrete for three kind of water to cement ratio

The density of concrete containing uncoated plastic aggregate decreases a little following an increase of water to cement ratio. However it is not the case for concrete containing sand coated plastic aggregate. The highest density for concrete containing coated plastic aggregate is obtained with water to cement ratio equal to 0.3 .

\subsection{Compressive strength of concrete}

Compression test are performed on 28 days aged concrete cylindrical specimens with a diameter of $10 \mathrm{~cm}$ and a height of $20 \mathrm{~cm}$. The same kind of specimens used for density evaluation, are then utilized for compression testing. Three different water to cement ratios and two coating condition are fixed for the concrete compressive strength evaluation.

Result of the compression testing shows that compressive strength of all kinds of concrete decreases 
as water to cement ratio increases. Compressive strength of concrete containing sand coated plastic coarse aggregate is higher than that of concrete with uncoated plastic aggregate, as shown in Figure 7. It is valid for three kind of water to cement ratio. 7 days aged concrete compression testing results are intended for controlling the concrete strength.

For all W/C ratios, concrete specimens containing uncoated plastic aggregate show only slight increase of 7 days compressive strength to 28 days compressive strength. In this case, the 28 days highest compressive strength of concrete specimens containing uncoated aggregate which is $14.25 \mathrm{MPa}$ given by the $\mathrm{W} / \mathrm{C}$ ratio equals to 0.28 , is still below the building minimum structural compressive strength of $17.5 \mathrm{MPa}$ based on normal cylinder specimen as stated in Indonesian National Standard SNI 03-2847-2002.

For two W/C ratios, a much better increase of compressive strength for 28 days concrete specimens containing coated plastic aggregate from its 7 days compressive strength. However it is not the case for concrete specimens containing coated aggregate with W/C equals 0.28 as it might experience bad compaction. The highest compressive strength for 28 days of concrete specimens containing coated aggregate is given by the $\mathrm{W} / \mathrm{C}$ equals 0.3 with a value of $18.16 \mathrm{MPa}$. It is almost near the minimum required compressive strength defined by the Indonesia National Standard SNI 03-2847-2002 as the tested specimens are smaller than cylinder stated in the Standard. As seen in Table 3, the uncoated plastic aggregate density is lower than one, resulting in disturbing the workability which in turn difficult to compact the fresh concrete as uncoated aggregate tends to separate. This situation could cause segregation of the materials. Uncoated plastic aggregate also has smooth surface and hydrophobia characteristic.

After crushing the specimens, observation to the concrete specimens containing uncoated plastic coarse aggregate indicates weak bonding at the interface zone between uncoated plastic aggregate and mortar. Examples of this situation are shown in Figure 8a, 8b and $8 \mathrm{c}$. It confirms low compressive strength of concrete containing uncoated coarse aggregate.

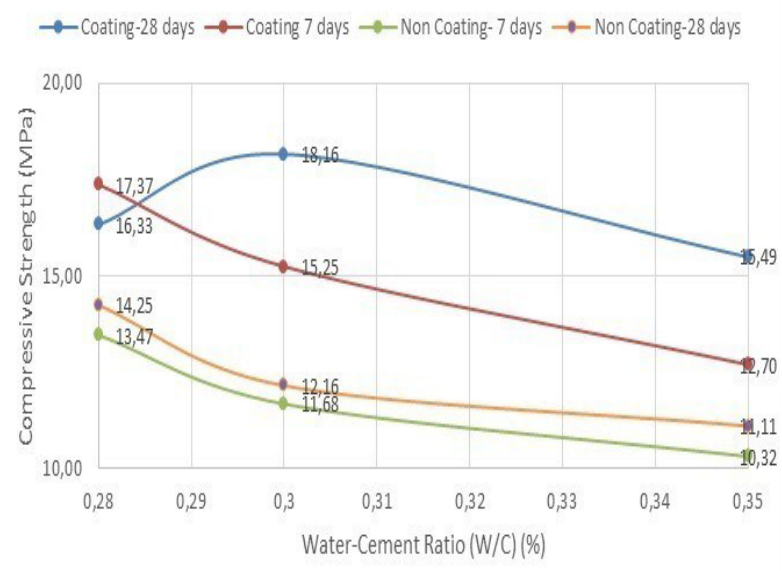

Fig. 7. Compressive Strength versus W/C and concrete age

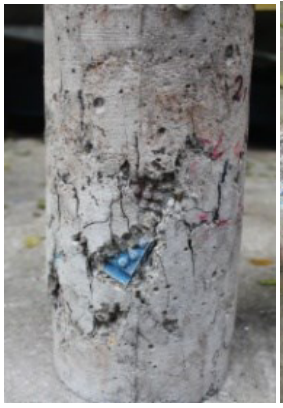

(a)

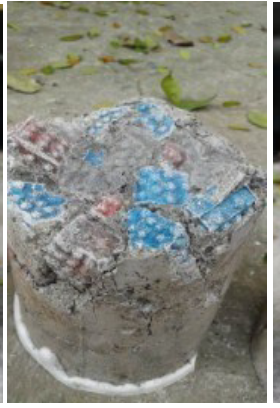

(b)

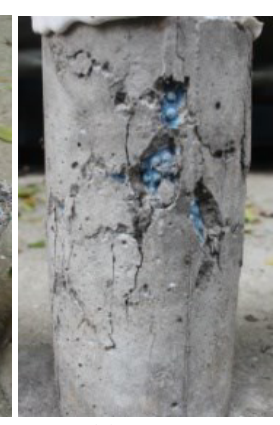

(c)
Fig. 8 Weak bonding between uncoated plastic aggregate and mortar

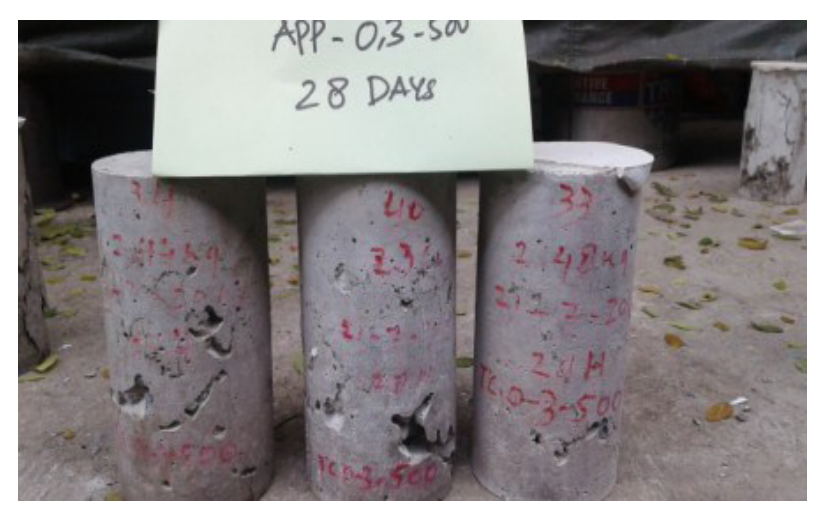

Fig. 9. Rupture of concrete cylinders containing uncoated plastic aggregate

Specimens of this kind show a relative distribution of crack on most of the specimen surface as the weak bonding are existed at interfaces of uncoated plastic aggregate and mortar in the specimens. Example of this condition is presented in Figure 9.

To overcome the problem, using the principle of Choi et al [9] to coat the plastic PET fine aggregates, the PP coarse aggregate is coated with sand. This method works as shown in Figure 7 and Figure 10 by the test results of compression testing of concrete containing sand coated PP coarse aggregate. Figure 10 shows a better bonding at the interface between sand coated PP coarse aggregate and mortar as less cracks appear over the whole surface of the specimens. Four concrete cylinders containing sand coated plastic aggregate show almost similar crack pattern where its base of cylinder experienced spalling.

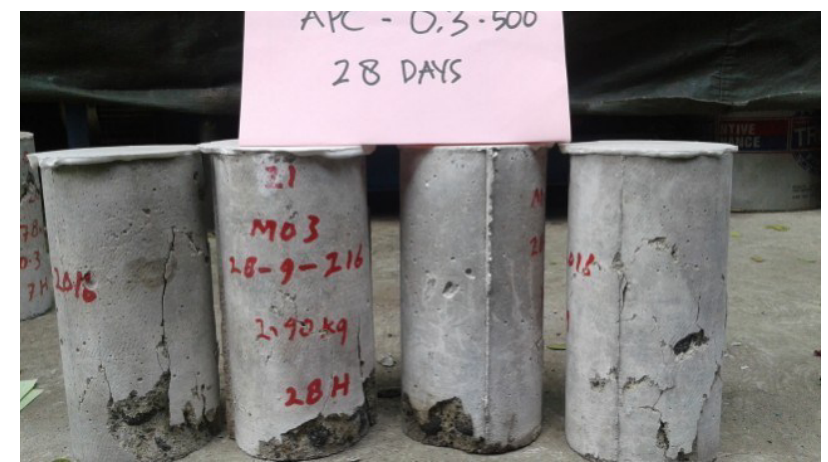

Fig. 10. Rupture of concrete cylinders containing coated plastic aggregate 


\section{Conclusion}

Result of the compression testing shows that compressive strength of all kinds of concrete studied, decreases as water to cement ratio increases. Compressive strength of concrete containing sand coated plastic coarse aggregate is higher than that of concrete with uncoated plastic aggregate. Based on the experiments results represented by the increase of compressive strength and also lesser crack appearance on the surface of concrete cylinder specimens, it can be concluded that the sand coating of the surface of plastic coarse aggregate is able to enhance the bond between coarse aggregate and mortar.

The authors convey their gratitude to the Ministry of Research Technology and Higher Education for Fundamental Research Grant support through Fiscal Year 2016. The same gratitude is also conveyed to the Head of Laboratory of Structure and Building Materials at Department of Civil Engineering, Faculty of Engineering, Universitas Indonesia for the facilities given in the experimental works.

\section{References}

1. L. Ferreira, J. de Brito, N. Saikia, Constr. Build. Mater. 36 (2012)

2. R. Ermawati, J. Riset Ind. 5, 3 (2011)

3. Y.W. Choi, D.J. Moon, Y.J. Kim, M. Lachemi, Constr. Build. Mater. 23 (2009)

4. M. Frigione, Waste Manage. $\mathbf{x x x}$ (2010).

5. S.C. Kou, G. Lee, C.S. Poon, W.L. Lai, Waste Manage. 29 (2009)

6. A.M. Mustafa Al Bakri, S.M. Tamizi, A.R. Rafiza, Y. Zarina, J. Asian Sci. Res. 1, 7 (2011)

7. G. Pamudji, H. Purnomo, I. Katili, I. Imran, P. 6th Civil Eng. Conf. Asia Region Jakarta (2013)

8. N. Saikia, J. de Brito, Constr. Build. Mater. 34 (2012)

9. Y.W. Choi, D.J. Moon, J.S. Chung, S.K. Cho, Cem. Concr. Res. 35 (2005)

10. M. Tanudjaja, S. Indrawan, J. Tek. Sipil 1, 2 (2004) 